\title{
HUBUNGAN STIGMA MASYARAKAT DENGAN KEPATUHAN MINUM OBAT PASIEN TB PARU DI PUSKESMAS PUHJARAK KECAMATAN PLEMAHAN KABUPATEN KEDIRI
}

\author{
Riris Nur Rizqiya $^{1^{*},}$ Emi Wuri Wuryaningsih ${ }^{2}$, Fitrio Deviantony ${ }^{3}$ \\ ${ }^{1}$ Prodi Sarjana Keperawatan Fakultas Keperawatan Universitas Jember, \\ ${ }^{2}$ Departemen Keperawatan Jiwa dan Komunitas Fakultas Keperawatan Universitas Jember, \\ ${ }^{3}$ Departemen Keperawatan Jiwa dan Komunitas Fakultas Keperawatan Universitas Jember, \\ *e-mail: riris6690@gmail.com
}

\begin{tabular}{|c|c|}
\hline & Abstract \\
\hline $\begin{array}{l}\text { Keywords: } \\
\text { tuberkulosis paru, } \\
\text { stigma } \\
\text { masyarakat, } \\
\text { kepatuhan minum } \\
\text { obat. }\end{array}$ & $\begin{array}{l}\text { TB Paru adalah penyebab utama penyakit di antara } 10 \text { penyebab } \\
\text { kematian teratas di seluruh dunia. Pengobatan TB minimal memerlukan } \\
\text { waktu } 6 \text { bulan sehingga memerlukan dukungan sosial yang baik kepada } \\
\text { penderita TB Paru. Penelitian ini bertujuan untuk menganalisis hubungan } \\
\text { stigma masyarakat dengan kepatuhan minum obat. Penelitian ini } \\
\text { menggunakan observasional dengan pendekatan cross-sectional. } \\
\text { Populasi penelitian adalah } 67 \text { pasien TB Paru dengan teknik } \\
\text { pengambilan datanya menggunakan teknik simple random sampling } \\
\text { didapatkan } 45 \text { sampel. Instrumen stigma masyarakat menggunakan } \\
\text { kuesioner Internalized Stigma of Mental Illness (ISMI) dengan r tabel } \\
\text { 0,62 dan reliabilitas 0,964 didapatkan } 28 \text { item yang valid. Instrumen } \\
\text { kepatuhan minum obat menggunakan kuesioner Morisky Medication } \\
\text { Adherence Scale (MMAS-8) dengan } r \text { tabel 0.8 dan reliabilitas 0,7 } \\
\text { didapatkan } 8 \text { item yang valid. Uji etika penelitian dilaksanakan di } \\
\text { Fakultas Ilmu Keperawatan Universitas Jember dengan nomor: } \\
\text { No.3561/UN25.1.14/SP/2020. Analisis data yang digunakan adalah uji } \\
\text { spearman. Hasil penelitian menunjukkan tidak ada hubungan antara } \\
\text { stigma masyarakat dengan kepatuhan minum obat pada pasien TB Paru } \\
\text { (p-value = 0,404;CI=95\%). Data demografi pasien didapatkan usia } \\
\text { responden TB Paru dengan nilai median 48.00 (Q1, Q3;35.00,61.00) } \\
\text { dengan min-max 15-70 dan jenis kelamin paling banyak adalah laki-laki } \\
\text { yaitu } 30 \text { responden (66.7\%). Hasil penelitian ini menunjukkan tidak ada } \\
\text { hubungan antara sitgma masyarakat dengan kepatuhan minum obat. } \\
\text { Puskesmas telah meningkatkan program edukasi tentang penyakit TB } \\
\text { Paru dan pencegahannya dimungkinkan menjadi salah satu menurunnya } \\
\text { stigma pada pasien TB Paru. Dukungan keluarga terhadap pengobatan } \\
\text { pasien ditandai dengan adanya pendampingan ketika berobat ke } \\
\text { Puskesmas. Puskesmas memiliki peran penting dalam meningkatkan } \\
\text { kepatuhan pengobatan pasien TB Paru baik secara langsung maupun } \\
\text { tidaklangsung. }\end{array}$ \\
\hline
\end{tabular}




\section{PENDAHULUAN}

TB Paru merupakan suatu penyakit menular yang disebabkan oleh kuman Mycobacterium Tuberculosis. Bakteri TB Paru juga dikenal sebagai bakteri tahan asam (BTA). Kelompok dari bakteri Mycobacterium selain Mycobacterium Tuberculosis yang bisa menimbulkan gangguan pada saluran nafas dikenal sebagai Mycobacterium Other Than Tuberculosis (MOTT) yang terkadang bisa mengganggu penegakan diagnosis pengobatan TB Paru tersebut (Kemenkes RI, 2018). Pengobatan TB Paru ini dilakukan secara rutin selama enam bulan. Pengobatan yang terputus atau tidak sesuai dengan standar Directly Observed Treatment Short-course (DOTS) dapat menyebabkan kekambuhan penyakit dan kemungkinan terjadinya resisten sekunder kuman tuberkulosis terhadap obat anti tuberkulosis atau Multi Drug Resistance (MDR) (Faizah et al., 2016).

TB Paru tetap menjadi penyebab utama kesehatan yang buruk dan salah satu dari 10 besar penyebab kematian di seluruh dunia. Kasus TB Paru sebagian berada di wilayah Asia Tenggara (44\%) di tahun 2018 (WHO, 2019). Indonesia pada tahun 2018 menempati peringkat ketiga dengan beban TB Paru tertinggi di dunia yaitu $8 \%$ sebanyak 420.994 kasus pada tahun 2017 (data per 17 Mei 2018) (Kemenkes, 2018). Provinsi Jawa Timur menempati urutan kedua di Indonesia dalam jumlah penemuan penderita tuberkulosis. Jumlah penemuan kasus baru BTA+ sebanyak 26.152 kasus Case Notification Rate $(\mathrm{CNR})=67 / 100.000$ penduduk dan jumlah penemuan semua kasus TB sebanyak 54.811 kasus Case Detection Rate $(\mathrm{CDR})=(46 \%) \quad($ Dinas Kesehatan Provinsi Jawa Timur, 2018). Menurut Dinas Kesehatan Kabupaten Kediri (2018) Kabupaten Kediri jumlah kasus TB Paru sebanyak 1709 kasus (53,50\%). UPTD Puskesmas Puhjarak Kecamatan Plemahan Kabupaten Kediri tercatat 70 kasus TB Paru dari bulan Juni 2019 sampai bulan Mei 2020.

Jumlah pasien terduga TB MDR dari tahun ke tahun mengalami pengingkatan. Pada tahun 2014 ada 1979 terduga TB MDR, meningkat lebih dari 2 kali lipat jika dibandingkan dengan tahun 2013. Sedangkan pada tahun 2015 sampai bulan Agustus jumlah terduga TB MDR sudah sebanyak 1.545 (Pemerintah Provinsi Jawa Timur, 2016). Menurut Prasetyo (2016) beberapa faktor yang mempengaruhi kepatuhan pengobatan diantaranya program pengobatan yang cukup lama sehingga penderita akan merasa bosan, efek samping dari obat-obatan yang menyebabkan penderita merasa tidak nyaman, sering lupa membawa obatobatan saat bepergian jauh, kurangnya pengetahuan dan pendidikan tentang penyakit TB Paru, sikap negatif pasien, penderita biasanya merasakan bahwa dirinya sudah sembuh karena tidak adanya gejala yang timbul.

Menurut penelitian Suriya (2018) pengobatan tuberkulosis paru harus dilakukan secara tuntas dan cukup lama oleh penderita tuberkulosis paru tersebut dan apabila kuman tuberkulosis paru aktif kembali maka akan terjadi yang namanya putus obat dan harus mengulang dari awal pengobatan tuberkulosis paru tersebut. Kepatuhan pengobatan TB Paru jika berhasil akan menyembuhkan pasien itu sendiri, mencegah kematian, mencegah kekambuhan, memutuskan rantai penularan serta mencegah terjadinya resisten dari bakteri terhadap Obat Anti Tuberkulosis (OAT).

Saranani dkk., (2019) bahwa tidak tercapainya angka kesembuhan TB Paru karena ketidakpatuhan berobat. Ketidakpatuhan menyebabkan angka kesembuhan penderita rendah, angka kematian yang tinggi, kekambuhan meningkat dan lebih fatalnya terjadinya resistensi bakteri terhadap beberapa obat anti tuberkulosis atau Multi Drug Resistance (MDR), sehingga menyebabkan 
penyakit TB Paru sangat sulit untuk disembuhkan (Sari dkk., 2016). Pasien yang mengetahui apabila tidak teratur dan tidak patuh dalam minum obat, pengobatan tuberkulosis akan diulang kembali dari awal dan pasien harus mengerti tentang penyakit tuberkulosis tersebut (Gunawan dkk., 2017).

Salah satu yang mempengaruhi ketidakpatuhan berobat pada pasien TB Paru adalah stigma masyarakat (Muhardiani, 2015). Stigma yang biasa dijumpai pada penderita TB antara lain penyakit tuberkulosis yang dikaitkan dengan adanya infeksi HIV, sebuah tindakan yang tidak bermoral dilakukan oleh penderita, penyakit dapat ditularkan lewat alat makanan, berasal dari masyarakat ekonomi menengah ke bawah dan orang yang merokok (Sari, 2018). Apabila orang sekitar mengetahui penderita menderita penyakit $\mathrm{TB}$, maka akan mendapatkan stigma yang buruk seperti dicemooh, tidak ingin berinteraksi dengan penderita dan mengatakan bahwa penyakit tersebut adalah sebuah kutukan (Masithoh, 2017).

Menurut Pribadi dkk (2017) pengobatan penyakit TB Paru saat ini bukan hanya difokuskan pada penderitanya saja tetapi juga pada langkah bagaimana menghilangkan stigma sosial yang sering terjadi karena pengaruh lingkungannya dengan cara mengubah persepsi masyarakat terhadap penyakit TB Paru melalui pembelajaran secara intensif tentang TB Paru. Penelitian ini bertujuan untuk mengetahui apakah ada hubungan antara stigma masyarakat dengan kepatuhan minum obat pasien TB Paru di Wilayah Kerja UPTD Puskesmas Puhjarak Kecamatan Plemahan Kabupaten Kediri.

\section{METODE PENELITIAN}

Penelitian ini menggunakan desain deskriptif korelasional dengan pendekatan cross sectional. Populasi penelitian ini adalah pasien TB Paru yang menjalani pengobatan di Wilayah Kerja UPTD Puskesmas Puhjarak Kecamatan Plemahan
Kabupaten Kediri sebanyak 70 orang. Perhitungan sampel menggunakan rumus lameshow diperoleh sebanyak 45 sampel.

$n=\frac{z^{2} \cdot N \cdot p \cdot q}{d^{2}(N-1)+z^{2} \cdot p \cdot q}$

$\mathrm{N}=41$

untuk mengantisipasi apabila ada responden yang dropout atau sebagainya, peneliti menambahkan $10 \%$ jumlah sampel, jadi besar sampel dalam penelitian ini adalah 45 sampel

Teknik pengambilan sampel yaitu probability sampling. Kriteria inklusi dalam penelitian ini antara lain penderita TB Paru yang menjalani pengobatan TB Paru, penderita TB Paru berusia 15-70 tahun dan penderita TB Paru yang bersedia menjadi responden. Sedangkan untuk kriteria eksklusi adalah penderita TB Paru yang diikuti dengan penyakit penyerta atau komplikasi dan lansia dengan hasil pengukuran MMSE $\leq 21$. Penelitian ini telah dilakukan uji etik melalui Komisi Penelitian Kesehatan Fakultas Keperawatan Universitas Jember dengan nomor: No.3561/UN25.1.14/SP/2020.

Instrumen penelitian untuk mengukur persepsi responden terhadap stigma masyarakat menggunakan kuesioner Internalized Stigma of Mental Illness (ISMI) $(\alpha$-cronbach $=0,964)$ yang terdiri dari 28 item pertanyaan. Indikator kuesioner stigma masyarakat antara lain alienation, stereotype, discrimination experience, stigma resistance. Instrumen penelitian untuk kepatuhan minum obat menggunakan kuesioner Morisky Medication Adherence Scale (MMAS-8) ( $\alpha$ cronbach $=0,7)$ terdiri dari 8 item pertanyaan. Uji statistik yang digunakan Spearman Test $(\mathrm{CI}=85 \%)$ dimana variabel kepatuhan minum obat skala data ordinal dan variabel stigma masyarakat dengan skala data interval.

\section{HASIL PENELITIAN}

Hasil Karakteristik Demografi pasien

TB Paru bisa dilihat pada tabel 1 .

Tabel 1. Karakteristik Responden 


\begin{tabular}{|c|c|c|}
\hline Variabel & $\begin{array}{c}\text { Jumlah } \\
\text { (n) }\end{array}$ & $\begin{array}{c}\text { Persentase } \\
(\%)\end{array}$ \\
\hline Umur (tahun) & - & $48 ; 15-70 *)$ \\
\hline \multicolumn{3}{|l|}{ Jenis Kelamin } \\
\hline Laki-laki & 30 & 66.7 \\
\hline Perempuan & 15 & 33.3 \\
\hline Total & 45 & 100.0 \\
\hline \multicolumn{3}{|l|}{ Pendidikan Terakhir } \\
\hline Tidak sekolah/SD & 21 & 46.6 \\
\hline SMP & 11 & 24.4 \\
\hline SMA & 10 & 22.2 \\
\hline Perguruan Tinggi & 3 & 6.7 \\
\hline Total & 45 & 100.0 \\
\hline \multicolumn{3}{|l|}{ Lama pengobatan } \\
\hline 2 minggu- 2 bulan & 9 & 20.0 \\
\hline$>2$ bulan- 6 bulan & 20 & 44.4 \\
\hline$>6$ bulan & 16 & 35.6 \\
\hline Total & 45 & 100.0 \\
\hline \multicolumn{3}{|l|}{ Akses obat } \\
\hline Rumah sakit & 0 & 0 \\
\hline Puskesmas & 45 & 100.0 \\
\hline Apotik & 0 & 0 \\
\hline Praktek dokter & 0 & 0 \\
\hline Klinik kesehatan & 0 & 0 \\
\hline Total & 45 & 100.0 \\
\hline \multicolumn{3}{|l|}{ Hidup dengan } \\
\hline Sendiri & 3 & 6.7 \\
\hline Keluarga & 42 & 93.3 \\
\hline Total & 45 & 100.0 \\
\hline \multicolumn{3}{|l|}{$\begin{array}{l}\text { PMO (Pengawas Minum } \\
\text { Obat) }\end{array}$} \\
\hline Ada & 38 & 84.4 \\
\hline Tidak & 7 & 15.6 \\
\hline Total & 45 & 100.0 \\
\hline \multicolumn{3}{|l|}{ Pekerjaan } \\
\hline Tidak bekerja & 11 & 24.4 \\
\hline Petani & 14 & 31.1 \\
\hline Buruh/karyawan & 12 & 26.7 \\
\hline PNS & 2 & 4.4 \\
\hline Pelajar & 3 & 6.7 \\
\hline Lain-lainnya & 3 & 6.7 \\
\hline Total & 45 & 100.0 \\
\hline \multicolumn{3}{|l|}{ Jenis obat } \\
\hline Tahap intensif & 9 & 20.0 \\
\hline Tahap lanjutan & 36 & 80.0 \\
\hline Total & 45 & 100.0 \\
\hline \multicolumn{3}{|l|}{ Waktu minum } \\
\hline $\begin{array}{l}07.001 \mathrm{x} \text { sehari saat perut } \\
\text { kosong }\end{array}$ & 15 & 33.3 \\
\hline $\begin{array}{l}13.001 \mathrm{x} \text { sehari saat perut } \\
\text { kosong }\end{array}$ & 5 & 11.1 \\
\hline $\begin{array}{l}19.001 x \text { sehari saat perut } \\
\text { kosong }\end{array}$ & 25 & 55.6 \\
\hline Total & 45 & 100.0 \\
\hline
\end{tabular}

Berdasarkan tabel 1 distribusi karakteristik responden TB Paru jenis kelamin paling banyak adalah laki-laki sebanyak $30(66.7 \%)$. Pendidikan terakhir sekolah dasar (SD) sejumlah 20 (44.4\%). Pekerjaan responden petani sebanyak 14 (31.1\%). Responden tinggal bersama keluarga sebanyak 42 (93.3\%). Ada Pengawas Minum Obat (PMO) yaitu sejumlah 38 (84.4\%). Untuk lama pengobatan pasien yaitu $>2$ bulan- 6 bulan sejumlah $20(44.4 \%)$. Obat yang diminum pasien adalah tahap lanjutan sekitar 36 $(80.0 \%)$. Pasien minum obat malam hari sebanyak 25 (55.6\%). Berdasarkan uji normalitas Shapiro-Wilk pada usia responden dihasilkan $\mathrm{p}=0.26$, sehingga dikatakan berdistribusi normal. Dikatakan berdistribusi normal apabila p> 0.05, sehingga didapatkan hasil nilai median umur responden adalah 48.00.

Tabel 2. Gambaran Persepsi Responde Terhadap Stigma Masyarakat

\begin{tabular}{lllll}
\hline Variabel & $\begin{array}{l}\text { Medi } \\
\text { an }\end{array}$ & $\begin{array}{l}\text { Min- } \\
\text { Maks }\end{array}$ & Q1 & Q3 \\
\hline $\begin{array}{l}\text { Stigma } \\
\text { Masyarakat }\end{array}$ & 66.00 & $57-74$ & 63.00 & 69.50 \\
\hline Sumber: & & & & \\
\hline
\end{tabular}

Sumber: Data primer peneliti, Agustus 2020

Hasil dari tabel 2 menunjukkan 50\% responden berada di atas skor 66.00 (minmaks; 57-74). Artinya apabila nilai median mendekati nilai maksimal maka persepsi responden terhadap stigma masyarakat tinggi. Diperoleh skor responden 66.00 $(48.84 \%)$ yang mana skor tersebut tidak mendekati nilai maksimal maka perepsi responden terhadap stigma masyarakat rendah

Tabel 3. Kepatuhan Minum Obat Pasien TB Paru di Wilayah Kerja UPTD Puskesmas Puhjarak Kecamatan Plemahan Kabupaten Kediri

*) median, min-max

Sumber: Data primer peneliti, Agustus 2020 


\begin{tabular}{lcc}
\hline \multicolumn{1}{c}{ Variabel } & $\begin{array}{c}\text { Jumlah } \\
\text { (n) }\end{array}$ & $\begin{array}{c}\text { Persentase } \\
(\boldsymbol{\%})\end{array}$ \\
\hline $\begin{array}{c}\text { Kepatuhan Minum } \\
\text { Obat }\end{array}$ & & \\
a. Tinggi & 26 & 57.8 \\
b. Sedang & 10 & 22.2 \\
c. Rendah & 9 & 20.0 \\
\hline \multicolumn{1}{c}{ Total } & 45 & 100.0 \\
\hline
\end{tabular}

Sumber: Data primer peneliti, Agustus 2020

Berdasarkan tabel 3 menunjukkan bahwa kepatuhan minum obat tinggi yaitu 26 pasien $(57.8 \%)$.

Tabel 4. Hubungan Stigma Masyarakat

Denga Kepatuhan Minum

Obat Pasien TB Paru di

Wilayah Kerja UPTD

Puskesmas Puhjarak

Kecamatan Plemahan

Kabupaten Kediri

\begin{tabular}{ccc}
\hline Variabel & $\begin{array}{c}\text { Stigma } \\
\text { Masyarakat }\end{array}$ & $\begin{array}{c}\text { Kepatuhan Minum } \\
\text { Obat }\end{array}$ \\
\hline $\mathbf{R}$ & 0.128 \\
\hline $\boldsymbol{P}$ value & 0.404 \\
\hline $\mathbf{N}$ & 45 \\
\hline Sumber: Data primer penelit, Agusus
\end{tabular}

Sumber: Data primer peneliti, Agustus 2020

Berdasarkan tabel 4 ini menunjukkan bahwa tidak ada hubungan antara stigma masyarakat dengan kepatuhan minum obat di Wilayah Kerja UPTD Puskesmas Puskesmas Puhjarak Kecamatan Plemahan Kabupaten

\section{PEMBAHASAN}

\section{Karakteristik Responden Pasien TB Paru}

Didapatkan nilai median usia responden yaitu 48.00 tahun yang artinya $50 \%$ responden berada di atas skor tersebut dan $50 \%$ berada di bawah skor tersebut dengan nilai min-max adalah 15-70. Menurut Kemenkes RI (2014) sekitar 75\% pasien TB Paru adalah kelompok usia yang paling produktif secara ekonomis (15-55 tahun). Menurut (Pribadi et al., 2017) stigma TB Paru dipengaruhi oleh usia kelompok produktif yaitu 30-50 tahun dengan stigma terhadap penderita TB Paru. Usia tersebut dikaitkan dengan pola pikir, gaya hidup dan pengalaman dimana orang dengan kelompok usia tersebut memiliki sikap yang berbeda terhadap penderita TB Paru. Hal ini dikarenakan sikap kelompok usia tersebut memiliki kekhawatiran tersendiri bila mana orang dalam kelompok usia tersebut terkena TB Paru.

Jenis kelamin laki-laki lebih banyak dibandingkan dengan perempuan yakni sebanyak 30 (66.7\%). Laki-laki lebih banyak merokok dan minum alkohol dimana dapat menurunkan sistem kekebalan dan pertahanan tubuh sehingga lebih rentan terpapar dengan agen penyebab TB Paru. Selain itu laki-laki mencari nafkah di luar sehingga banyak melakukan kegiatan aktivitas dan melakukan kontak dengan orang lain yang tidak diketahui apakah orang tersebut positif TB Paru atau tidak. Perempuan lebih waspada terhadap penyakit yang dideritanya karena tahu akan menularkan kepada keluarganya sehingga mereka akan berusaha mencari pengobatan agar tidak menularkan penyakitnya tersebut (Rojali \& Noviatuzzahrah, 2018).

Pendidikan terakhir responden yakni Sekolah Dasar (SD) sebanyak 20 (44.4\%). Salah satu faktor penyebab terjadinya peningkatan TB Paru salah satunya pendidikan. Semakin tinggi pendidikan seseorang maka semakin tinggi ilmu pengetahuan tentang kesehatan yang dimiliki sehingga menimbulkan kesadaran untuk berperilaku hidup lebih sehat. Pendidikan pasien berpengaruh terhadap kepatuhan pengobatan apabila seseorang terpapar penyakit salah satunya TB Paru, dapat mempengaruhi kepatuhan minum obat sehingga menjadikan keberhasilan pengobatan dan sembuh dari penyakit TB Paru (As \& Keliat, 2020).

Pekerjaan responden sebagai petani dengan jumlah 14 (31.1\%). Jenis pekerjaan juga berdampak pada kehidupan keluarga seperti konsumsi, kondisi fisik rumah yang kurang memenuhi standar dan kemampuan dalam pemeliharaan kesehatan. Menurut Rahmah dkk., (2018) faktor lingkungan kerja mempengaruhi seseorang terpapar suatu kondisi penyakit. Contohnya lingkungan kerja yang buruk berpotensi 
terinfeksi oleh bakteri TB Paru antara lain sopir, buruh, tukang becak dan lain sebagainya dibandingkan dengan pekerjaanya di perkantoran. Pekerjaan yang tidak mengikat waktu membuat responden mempunyai waktu untuk memanfaatkan pelayanan kesehatan dengan baik (Windiyaningsih, Abidin, \& Murtiani, 2017).

Responden tinggal bersama keluarga yakni sebanyak 42 (93.3\%). Dukungan keluarga merupakan hal yang paling penting dan dibutuhkan karena dengan pasien yang berumur dewasa muda ataupun dewasa tua akan merasa diperdulikan seperti pada saat berobat pasien akan didampingi oleh anggota keluarganya sehingga dorongan yang diberikan kepada pasien supaya patuh terhadap pengobatan akan dilaksanakan dengan baik (Rojali \& Noviatuzzahrah, 2018). Keluarga melakukan dukungan dengan mengingatkan minum obat dan membantu pencegahan penularan (Fatha, 2018). Dengan adanya dukungan keluarga yang diberikan oleh keluarga akan mempengaruhi kesadaran pasien dengan TB Paru untuk patuh terhadap pengobatannya (Wulandari, Rantung, \& Malinti, 2020).

Terdapat PMO yakni sebanyak 38 (84\%). PMO berperan aktif dalam memberikan motivasi pada pasien TB Paru untuk berobat yang akan memberikan dampak terhadap keaktifan pasien TB Paru untuk memeriksakan diri ke Puskesmas. Puskesmas dapat melibatkan keluarga pasien sebagai PMO di rumah untuk membantu mengontrol kepatuhan minum obat pasien TB Paru. Hal ini menunjukkan bahwa kecenderungan semakin baik peran PMO maka keberhasilan pengobatan juga akan semakin baik dan meningkat dan sebaliknya apabila semakin buruk PMO dalam pengobatan TB Paru maka keberhasilan pengobatan semakin kecil (Situmeang, Sulistyani, \& Utami, 2020).

Lama pengobatan responden $>2$ bulan-6 bulan sejumlah 20 (44.4\%). Menurut (Y. Sari, 2018) pasien yang menjalani pengobatan $>3$ bulan dapat merasakan perasaan positif dan muncul suatu keyakinan dalam dirinya bahwa dirinya tetap dapat memberikan kontribusi bagi lingkungan sekitar, masih bisa menyelesaikan pekerjaanya dengan baik, merasa nyaman berdekatan dengan orang lain. Selain itu pasien TB Paru akan mengalami penurunan dampak negatif dari penyakit TB Paru baik secara fisik maupun psikologis.

Obat yang dimimun jenis tahap intensif dan lanjutan yakni sebanyak 36 (80.0\%). Tahap lanjutan selama 4 bulan, dalam tahap ini pasien diwajibkan mengambil dan meminum obat dengan memilih 3 hari saja dalam seminggu, contoh hari senin, rabu, dan jumat. Pengobatan tahap lanjutan ini dilakukan untuk membunuh kuman persister sehingga pasien dapat sembuh dan mencegah terjadinya kekambuhan lagi.

Kebanyakan responden minum obat pada malam hari yakni sebanyak 25 (55.6\%). Menurut Kemenkes RI (2014) mengatakan tanda dan gejala utama pasien TB Paru salah satunya adalah berkeringat di malam hari tanpa melakukan kegiatan fisik. Sehingga peneliti berasumsi bahwa pasien yang meminum obat TB Paru di waktu malam hari memiliki tanda dan gejala berkeringat di malam hari tanpa melakukan kegiatan fisik untuk meredakan tanda dan gejala penyakitnya tersebut.

\section{Gambaran Persepsi Responden Terhadap Stigma Masyarakat}

Hasil analisis deskriptif stigma masyarakat pada pasien TB Paru di Wilayah Kerja UPTD Puskesmas Puhjarak Kecamatan Plemahan Kabupaten Kediri menunjukkan bahwa rata-rata stigma masyarakat pasien TB Paru sebesar 66.00. Semakin tinggi nilai stigma maka akan semakin tinggi stigma yang dirasakan oleh pasienTB Paru. Nilai tersebut menunjukkan bahwa stigma masyarakat pasien TB Paru telah mencapai $73.92 \%$ (dari nilai maksimal 112) yang artinya $50 \%$ responden berada di atas skor tersebut 
dan $50 \%$ berada di bawah skor tersebut (Min-Maks= 28-112). Stigma masyarakat dibedakan menjadi 4 indikator yaitu pengasingan, stereotipe, pengalaman diskriminasi dan resistensi stigma (Schied dan Brown, 2010).

Stigma yang dimaksud adalah stigma yang dipersepsikan oleh penderita TB Paru sebagai akibat dari perilaku orang-orang disekelilingnya. Stigma merupakan salah satu label negatif yang diberikan oleh seseorang/kelompok orang kepada orang lain, yang mana stigma tersebut dapat berkaitan dengan adanya suatu penyakit kronis maupun menular (Y. Sari, 2018). Setelah terdiagnosa menderitaTB Paru, kemudian pasien terstigma oleh masyarakat maka pasien akan merasa sebagai sumber penularan bagi orang lain sehingga penderita TB Paru merasa malu, mengisolasi diri dan merahasiakan penyakit mereka (Husnaniyah et al., 2017). Apabila pasien dengan tuberkulosis mendapat stigma negatif maka akan berdampak terhadap keterlambatan pengobatan, pencegahan dan kebijakan yang berkaitan dengan penyakit tersebut (Herwati, Abdurakhman, \& Rundamintasih, 2020).

Menurut Husnaniyah dkk., (2017) munculnya anggapan negatif masyarakat terhadap orang dengan penyakit menular seperti TB Paru bisa disebabkan kurangnya pemahaman/pengetahuan masyarakat tentang penyakit menular, khususnya tentang penyakit TB Paru tersebut. Selain itu apabila stigma masyarakat sudah melekat pada penderita akan mempengaruhi interaksi mereka dengan masyarakat. Stigma masyarakat tentang penyakit TB Paru dapat menimbulkan beberapa permasalahan seperti harga diri rendah, isolasi sosial dan gangguan citra tubuh (Husnaniyah, 2017). Oleh karena itu stigma negatif harus dihilangkan dari lingkungan sekitar untuk mengontrol penyakit/TB Paru yang dialami oleh pasien tersebut

\section{Kepatuhan Minum Obat}

Hasil penelitian menunjukkan bahwa tingkat kepatuhan minum obat pasien tinggi paling banyak yakni 26 (57.8\%), sedangkan kepatuhan minum obat sedang yakni sejumlah $10(22.2 \%)$ dan kepatuhan minum obat rendah yakni sebanyak 9 (20.0\%). Kepatuhan pasien dalam pengobatan yang dilakukan berkenaan dengan kemampuan dan kemauan pasien itu sendiri yaitu dengan mengikuti saran yang diberikan oleh petugas kesehatan, menjaga pola hidup, jadwal periksa yang diderita dan aturan pengobatan (Putri dan Isfandira, 2013). Sikap patuh merupakan suatu perilaku penting yang harus dimiliki oleh setiap individu yang sedang menjalankan suatu pengobatan, terutama dalam pengobatan penyakit kronis.

Alasan yang paling banyak diungkapkan oleh responden yang patuh dalam pengobatan adalah bahwa mereka ingin sembuh dari penyakit TB Paru dan bisa beraktivitas secara normal. Dukungan keluarga dan orang terdekat sangat membantu dalam proses penyembuhan pasien TB Paru yang mana bisa membuat pasien tersebut patuh dalam pengobatan (Safii, Putri, \& Suparto, 2015). Selain itu menurut Safitri dkk., (2015) dukungan dari keluarga, bagian penting dalam keberhasilan pengobatan pasien tuberkulosis adalah adanya pendidikan dan pengetahuan dari pihak Puskesmas. Dengan adanya pendidikan dan pengetahuan dari pihak Puskesmas bisa membantu pasien TB Paru termotivasi untuk patuh minum obat agar pasien tersebut sembuh dari penyakitnya.

Kepatuhan minum obat pada pasien TB Paru merupakan upaya untuk meningkatkan angka kesembuhan dan menekan peningkatan jumlah kasus TB MDR.

Hubungan Stigma Masyarakat dengan Kepatuhan Minum Obat Pasien TB Paru di Wilayah Kerja UPTD Puskesmas Puhjarak Kecamatan Plemahan Kabupaten Kediri 
Hasil uji statistik didapatkan nilai p-value sebesar 0.404, yang artinya tidak terdapat hubungan antara stigma masyarakat dengan kepatuhan minum obat pasien TB Paru di Wilayah Kerja UPTD Puskesmas Puhjarak Kecamatan Plemahan Kabupaten Kediri. Peneliti berasumsi bahwa tidak terdapat hubungan dikarenakan pasien TB Paru tidak memberikan informasi kepada masyarakat terkait sakitnya. Setelah terdiagnosa menderita TB Paru, stigma yang muncul pada pasien adalah mereka merasa sumber penularan bagi orang lain sehingga kebanyakan dari pasien TB Paru merasa malu, mengisolasi diri dan merahasiakan penyakitnya (Husnaniyah et al., 2017).

Penelitian yang dilakukan oleh peneliti sesuai dengan hasil penelitian yang dilakukan oleh Michael dkk (2014) yang mana hasil penelitian menyatakan bahwa pasien merasa takut terhadap stigmatisasi yang ada di masyarakat sehingga pasien menyembunyikan sakitnya (penyakitnya) dan tidak memberitahu/ruang bagi orang lain untuk melakukan stigmatisasi pada dirinya. Pasien TB Paru di Kecamatan Plemahan Kabupaten Kediri juga memiliki perilaku yang sama yaitu membatasi pengetahuan tentang penyakit mereka (TB Paru) dari masyarakat dan hanya keluarga/orang terdekat yang mengetahui keadaannya. Sehingga di Wilayah Kerja UPTD Puskesmas Plemahan Kecamatan Plemahan Kabupaten Kediri tidak ada stigma yang dapat mempengaruhi terhadap kepatuhan minum obat .

Peneliti menganalisis bahwa tidak terdapat hubungan disebabkan karena adanya dukungan yang telah diberikan oleh keluarga/orang terdekat dan pihak puskesmas (petugas kesehatan) telah memberikan pendidikan dan pengetahuan tentang penyakit TB Paru. Dukungan keluarga menjadi hal yang dapat mempengaruhi kepatuhan minum obat pasien TB Paru. Dukungan keluarga sangat menunjang keberhasilan pengobatan TB Paru karena dukungan keluarga diperlukan untuk mendorong pasien TB Paru dengan menunjukkan kepedulian dan simpati (Herwati et al., 2020).

Menurut Suriya, (2018) dukungan dari seluruh anggota keluarga sangat penting dalam proses penyembuhan dan pemulihan penderita terhadap salah satu keluarga yang menderita TB Paru. Beberapa dukungan keluarga yang diberikan antara lain penghargaan lewat pujian positif untuk kepatuhan minum obat, dukungan instrumental berupa menemani anggota keluarga yang sakit untuk berobat dan dukungan informasi pada penderita TB Paru yaitu keluarga mengetahui informasi kesehatan terkait penyakit TB Paru yang diderita oleh anggota keluarga.

Selain dukungan keluarga, peran petugas kesehatan yaitu memberikan informasi (pendidikan dan pengetahuan) yang benar mengenai penyakit TB Paru setelah berobat dapat memberikan stigma rendah bagi pasien dan menjadikan pasien tuberkulosis patuh terhadap pengobatan. Pendidikan dan pengetahuan yang diberikan akan membantu masyarakat semakin sadar tentang penerimaan pasien TB Paru yang berada disekitarnya dan pasien TB Paru semakin sadar akan pentingya pengobatan. Hal ini sesuai dengan penelitian Damalita (2014) bahwa masyarakat yang telah diberikan pendidikan kesehatan oleh petugas kesehatan atau media elektronik memiliki stigma yang rendah terhadap seseorang yang mengalami penyakit kronis.

Selain itu menurut Hasudungan dan Wulandari (2020) tentang pengetahuan responden terhadap stigma penyakit $\mathrm{TB}$ Paru memiliki hubungan yang signifikan dimana semakin tinggi tingkat pengetahuan pasien dalam mengetahui tanda dan gejala, penyebab, penularan, komplikasi, pengobatan dan pencegahan penyakit TB Paru maka akan semakin rendah stigma tentang penyakitnya. Stigma kerap sekali melekat pada masalah kesehatan, khususnya TB Paru. Alasan mengapa bisa muncul stigma pada TB 
Paru salah satunya adalah karena penularannya dan pengetahuannya yang kurang tepat akan penyebabnya (Hasudungan \& Wulandari, 2020).

Stigma yang didapat oleh pasien TB Paru mempunyai dampak negatif, yaitu perasaan malu, rendah diri, isolasi sosial hingga depresi dapat terjadi akibat stigma tersebut. Kondisi ini dapat mengakibatkan terhambatnya proses pengobatan akibat adanya penghindaran dari pasien, akibatnya tidak pasien putus obat dan berefek pada proses pengobatan dan penyembuhan (Endria dan Yona, 2019)

\section{SIMPULAN DAN SARAN}

\section{SIMPULAN}

a. Gambaran persepsi responden terhadap stigma menunjukkan $50 \%$ responden berada di atas skor 66.00 (min-maks; 57-74). Artinya apabila nilai median mendekati nilai maksimal maka persepsi responden terhadap stigma masyarakat tinggi. Diperoleh skor responden $66.00(48.84 \%)$ yang mana skor tersebut tidak mendekati nilai maksimal maka perepsi responden terhadap stigma masyarakat rendah.

b. Kepatuhan minum obat pada pasien TB Paru tinggi 26 responden $(57.8 \%)$.

c. Tidak ada hubungan yang signifikan antara stigma masyarakat dengan kepatuhan minum obat pada pasien TB Paru di Wilayah Kerja UPTD Puskesmas Puhjarak Kecamatan Plemahan Kabupaten Kediri

\section{SARAN}

Perawat tetap konsisten dalam memberikan edukasi kepada masyarakat dan melibatkan masyarakat untuk memberikan dukungan sosial kepada penderita tuberkulosis paru guna meningkatkan kepatuhan dalam pengobatan dan produktifitasnya seharihari.

\section{DAFTAR PUSTAKA}

As, P. P. Dan B. A. Keliat. 2020. Faktor Yang Mempengaruhi Kepatuhan Klien Terhadap Pengobatan Tuberkulosis Resistan Obat. Jurnal Ilmu Keperawatan. 3(2):149-160.

Damalita. 2014. Faktor-Faktor yang mempengaruhi Stigma Masyarakat Terhadap ODHA. Naskah Publikasi. STIKES 'Aisyiyah Yogyakarta.

Dewanty I L,Titik H, Tri P K. (2016). Kepatuhan berobat penderita TB paru di Puskesmas NguntoronadiI Kabupaten Wonogiri. Jurnal Kesehatan. 1 (1):39-43

Dinas Kesehatan Kabupaten Kediri. 2018. Profil Kesehatan Kabupaten Kediri Tahun 2018. Kediri

Dinas Kesehatan Propinsi Jawatimur. 2006. Profil Kesehatan Propinsi Jawa Timur 2017. Nucleic Acids Research. 34(11):E77-E77.

Endria, V. Dan S. Yona. 2019. Depresi Dan Stigma $\mathrm{Tb}$ Dengan Kualitas Hidup Pasien Tu- Berkulosis Paru (Depression And Tb Stigma With The Quality Of Life Of Patients With Pulmonary Tu- Berculosis). 000:2128.

Faizah, U., F. Agiananda, N. S. Winarsih, T. T. Ginting, F. Isbaniah, S. D. Elvira, Dan L. E. S. I. G. 2016. Gangguan Psikiatri Pasien Tb-Mdr ( Multi Drug Resistant ) Dan Stres Psikososial Yang Memengaruhi Di Rsup Persahabatan. J Indon Med Assoc. 66:10:473-480.

Fatha, E. M. 2018. Penyebab Drop Out Pengobatan Tuberkulosis Paru Di Puskesmas Kedungmundu Kota Semarang.

Gunawan, A. R. S., R. L. Simbolon, dan D. Fauzia. 2017. Faktor-Faktor yang Mempengaruhi Tingkat Kepatuhan Pasien Terhadap Pengobatan Tuberkulosis Paru di Lima Puskesmas Se-Kota Pekanbaru. JOM FK. 4(2):1-20.

Hasibun, R. A., \& Hidayah, N. (2019). 
Gambaran Tingkat Pengetahuan, Sikap Dan Tindakan Pasien Tuberkulosis Terhadap Kejadian $\mathrm{Tb}$ Paru Di Puskesmas Medan Area Selatan. Jurnal Kesehatan. 12(2): 238-251.

Hasudungan, A. Dan I. S. M. Wulandari. 2020. HUBUNGAN Pengetahuan Penderita Tbc Terhadap Stigma Penyakitnya Di Wilayah Kerja Puskesmas Parongpong Kecamatan Parongpong Kabupaten Bandung Barat. CHMK Nursing Scientific Journal. 4(1):171-177.

Herwati, C., R. N. Abdurakhman, Dan N. Rundamintasih. 2020. Peran Dukungan Keluarga , Petugas Kesehatan Dan Perceived Stigma Dalam Meningkatkan. Jurnal Kesehatan Masyarakat Indonesia. 15(1):19-23.

Husnaniyah, D., M. Lukman, Dan R. D. Susanti. 2017. Faktor-Faktor Yang Berpengaruh Terhadap Harga Diri (Self Esteem) Penderita Tuberkulosis Paru Di Wilayah Eks Kawedanan Indramayu. The Indonesian Journal Of Health Science. 9(1):1-12.

Kemenkes RI. 2014. Pedoman Nasional Pengendalian Tuberkulosis. Jakarta: Kementerian Kesehatan RI.

Kemenkes RI. 2018. Hasil Utama Riskesdas 2018. Jakarta: Kementerian Kesehatan RI.

Kemenkes RI. 2018. Pusat Data dan Informasi. Jakarta Selatan. Who 2019.

Masithoh, A. R., I. Qasanah, Dan D. Hertiana. 2017. Pengaruh Terapi Psikoedukasi Keluarga Terhadap Harga Diri Penderita Tbc Di Wilayah Kerja Puskesmas Undaan Kabupaten Kudus Tahun 2015. 529-538.

Michael, O. O., T. W. Adelani, B. Y. Aderemi, H. Oluyedun, B. Pharm, dan P. Victor. 2014. Factor Influencing Clients' Compliance with Therapy of Tuberculosis in Ibadan, Nigeria. IOSR Journal of Nursing and Health Science (IOSR-JNHS). Vol 3(1): 57-62.
Muhardiani, Mardjan, Dan Abrori. 2015. Hubungan Antara Dukungan Keluarga, Motivasi Dan Stigma Lingkungan Dengan Proses Kepatuhan Berobat Terhadap Penderita Tb Paru Di Wilayah Kerja Puskesmas Gang Sehat. Jurnal Mahasiswa Dan Peneliti Kesehatan. 17-26.

Pernadi, M. O., Suyanto, Dan R. L. Simbolan. 2015. Persepsi Penderita Terhadap Pengobatan Dan Kesembuhan Penyakit Tuberkulosis Paru Di Kota Pekanbaru. JOM FK. 2(2):1-14.

Prasetyo. M. T. 2016. Pengaruh Terapi Suportif: Kelompok Terhadap Kepatuhan Minum Obat Klien TB Paru di Wilayah Puskesmas Patrang Kabupaten Jember. Skripsi. Program Studi Ilmu Keperawatan: Universitas Negeri Jember

Pribadi, T., E. Trismiyana, Dan N. Maria. 2017. PENGETAHUAN Masyarakat Dengan Stigmatisasi Terhadap Penderita Tb Paru Di Wilayah Kerja Puskesmas Karang Anyar Kabupaten Lampung Selatan 2017. 11(4):265270.

Rahmah, P. M., I. S. A. Tunru, Dan Yusnita. 2018. Hubungan Tingkat Pendapatan Terhadap Keberhasilan Pengobatan Pada Pasien Tuberkulosis Di Puskesmas Kecamatan Johar Baru Jakarta Pusat Tahun 2016. Jurnal Profesi Medika. 12(1):7-12.

Rojali Dan Noviatuzzahrah. 2018. Faktor Risiko Kepatuhan Pengobatan Pada Penderita Tb Paru Bta Positif. Jurnal Kesehatan. 9(1):70-79.

Safii, S. T. Putri, Dan T. A. Suparto. 2015.

Gambaran Kepatuhan Pasien Tuberkulosis Paru Terhadap Regimen Terapeutik Di Puskesmas Padasuka Kota Bandung. Jurnal Pendidikan Keperawatan Indonesia. 1(2):98-104. Saranani, M., Yuniar Syanti Rahayu, D., \& Ketrin, K. 2019. Management Casus : Pemenuhan Kebutuhan Oksigenasi pada Pasien Tuberculosis 
Paru. Health Information : Jurnal Penelitian, 11(1), 26-32

Sari, I. D., R. Mubasyiroh2, Dan S. Supardi. 2016. Hubungan Pengetahuan Dan Sikap Dengan Kepatuhan Berobat Pada Pasien Tb Paru Yang Rawat Jalan Di Jakarta Tahun 2014. Media Litbangkes. 26(4):243-248.

Sari, Y. 2018. GAMBARAN Stigma Diri Klien Tuberkulosis Paru ( Tb Paru ) Yang Menjalani Pengobatan Di Puskesmas Malingping (Self Stigma Of Pulmonary Tuberculosis Among Patients Seeking). Media Ilmu Kesehatan. 7(1):43-50.

Scheid, T. L dan T. N. Brown. 2010. A Handbook for The Study of Mental Health: Social Contexts, Tjeories, and Systems. Second Edition. America: Canbridge University Press

Situmeang, L., S. Sulistyani, Dan T. F. C. T. Utami. 2020. Faktor Yang
Berhubungan Dengan Kepatuhan Berobat Penderita Tb Paru Di Puskesmas Kota Yapen. Serui. Jurnal Keperawatan Tropis Papua. 03:133138.

Suriya, M. 2018. FAKTOR-Faktor Yang Berhubungan Dengan Kualitas Hidup Lubuk Alung Sumatera Barat. Jurnal Keperawatan Abdurrab. 2(1):29-38.

Windiyaningsih, C., Z. Abidin, Dan F. Murtiani. 2017. Faktor-Faktor Yang Berhubungan Dengan Kepatuhan Berobat Pada Penderita Tuberkulosis Paru. The Indonesian Journal of Infectious Diseases. 4(1)

Wulandari, I. S. M., J. Rantung, Dan E. Malinti. 2020. Faktor Yang Berhubungan Dengan Kepatuhan Minum Obat Pasien Tbc Di Wilayah Ker- Ja Puskesmas Parongpong. Jurnal Keperawatan Muhammadiyah. 5(1):128-134. 